\title{
Brain correlates of discourse processing: An fMRI investigation of irony and conventional metaphor comprehension
}

\author{
Zohar Eviatar $^{\mathrm{a}, *}$, Marcel Adam Just ${ }^{\mathrm{b}}$ \\ ${ }^{a}$ Institute of Information Processing and Decision Making, Psychology Department, University of Haifa, Haifa 31905, Israel \\ ${ }^{\mathrm{b}}$ Center for Cognitive Brain Imaging, Carnegie-Mellon University, United States
}

Received 26 August 2005; received in revised form 30 April 2006; accepted 4 May 2006

Available online 23 June 2006

\begin{abstract}
Higher levels of discourse processing evoke patterns of cognition and brain activation that extend beyond the literal comprehension of sentences. We used fMRI to examine brain activation patterns while 16 healthy participants read brief three-sentence stories that concluded with either a literal, metaphoric, or ironic sentence. The fMRI images acquired during the reading of the critical sentence revealed a selective response of the brain to the two types of nonliteral utterances. Metaphoric utterances resulted in significantly higher levels of activation in the left inferior frontal gyrus and in bilateral inferior temporal cortex than the literal and ironic utterances. Ironic statements resulted in significantly higher activation levels than literal statements in the right superior and middle temporal gyri, with metaphoric statements resulting in intermediate levels in these regions. The findings show differential hemispheric sensitivity to these aspects of figurative language, and are relevant to models of the functional cortical architecture of language processing in connected discourse.
\end{abstract}

(C) 2006 Elsevier Ltd. All rights reserved.

Keywords: Figurative language; Irony; Metaphor; Pragmatics; fMRI

\section{Introduction}

Scholars of language pragmatics and discourse have long been interested in the manner in which people understand the meanings of utterances that are not intended literally but rather figuratively. For example, Gibbs (1994) makes an eloquent argument that irony is a common form of thought (and not just language) because it is a method for juxtaposing one's expectations with the realities of life, and treating the discrepancy with some general approach to life, such as humor or bitterness or knowingness. Irony is one of the lenses through which we see the world, and through which we describe the world to others. Similarly, metaphor is a way of understanding one concept in terms of another, transferring knowledge from one domain to another, in ourselves and in those with whom we communicate. The comprehension of both irony and metaphor requires non-literal interpretation that extends beyond first-order lexical and syntactic processing. For example, irony and metaphor

\footnotetext{
* Corresponding author. Tel.: +972 4824 9668; fax: +972 48240966.

E-mail address: zohare@ research.haifa.ac.il (Z. Eviatar).
}

both require that the comprehender know something about the speaker's beliefs and intentions and use that knowledge in generating the non-literal interpretation.

In the last decades, studies of the functional architecture of linguistic abilities in the brain have examined the relative abilities of the two cerebral hemispheres, and have revealed that although the left hemisphere (LH) is dominant for the majority of language functions, the right hemisphere $(\mathrm{RH})$ is involved in the processes of narrative construction (e.g. Gernsbacher \& Robertson, 1999) and discourse representation (e.g. Kuperberg et al., 2000; Long \& Baynes, 2002). The involvement of the RH in the processing of verbal irony (e.g. McDonald, 2000), conventional and novel metaphors (e.g. Rapp, Leube, Erb, Grodd, \& Kircher, 2004; Sotillo et al., 2005), and predictive and coherence inferences (Beeman, Bowden, \& Gernsbacher, 2000) have been examined. The present study examined patterns of activation levels as measured by fMRI in the brain while participants were reading utterances that differed in their discourse value: literal, conventional metaphors, and irony. The empirical question under investigation here has two parts: first, does the processing of literal and nonliteral statements result in activation of the same brain areas? Second, will the distribution of activation be the 
same for two types of figurative language, irony and metaphor? The theoretical goal is to formulate new, testable hypotheses (based on the empirical findings) concerning the roles of the participating cortical areas in the two hemispheres in the comprehension of figurative language.

\subsection{Pragmatic models of the comprehension of figurative language}

In general, theories of pragmatics have conceptualized both types of nonliteral language in terms of similar mechanisms. The standard pragmatic model (Grice, 1975; Searle, 1979) proposed that both violate the truthfulness maxim, signaling the comprehender that the utterance requires more than literal processing. Metaphoric utterances need not be literally true ${ }^{1}$ (a politician is not literally a lightning rod), whereas ironic statements are falsified by the context (the hearer knows that it is raining heavily, when the speaker says, 'What a great day for a picnic'). For metaphors, the incoherence of the statement is solved by relating the attributes of the vehicle (the lightning rod) to those of the target. For irony, coherent interpretation requires understanding that the speaker is pretending, and actually intending a meaning opposite of what they are saying. There is nothing inherently figurative about the statement 'What a great day for a picnic', except the fact that it cannot be true in the context of heavy rain. The position of the standard model of pragmatics is that the literal interpretation of the utterance is always processed, and then reprocessed in order for the correct meaning to be extracted.

This standard model has been repeatedly disconfirmed by findings that response times to conventional metaphors and ironies are not slower than to literal statements (e.g. Giora, 1997). More recent models have proposed that under some circumstances both types of meaning may be processed concurrently, without computing the literal meaning of the expression first (Colston \& Gibbs, 2002; Gernsbacher, Keysar, Robertson, \& Werner, 2001; Gibbs, 2001; Giora, 1999). The majority of models propose that a common mechanism is used to comprehend both literal and nonliteral language, where ironies and metaphors are seen as a source of polysemy in a language (e.g. Cacciari \& Glucksberg, 1994). Thus, the timeline of comprehension of these utterances may resemble the process of lexical access for ambiguous words (e.g. Swinney, 1979), with both the literal and the nonliteral meaning activated initially, and the inappropriate meaning inhibited as a result of the effects of context. An active field of research examines this timeline, and the interaction of lexical and contextual effects on the activation of literal and nonliteral meanings (e.g. Peleg, Giora, \& Fein, 2001; Vu, Kellas, Metcalf, \& Herman, 2000; Colston \& Gibbs, 2002). Giora (1999) has emphasized the importance of the lexicalization of nonliteral language, showing that in terms of her graded salience hypothesis, salience is determined first and foremost by the lexical status of the utterance. According to this view, famil-

\footnotetext{
1 We adhered to the argument that metaphors and similes assert the same relationship between vehicle and topic, and some of our metaphoric sentences were technically similes, in that they included the words 'like' or 'as'. See Appendix A. We refer to both as metaphors in the article.
}

iar ('frozen' or 'dead') metaphors and ironies may be processed like very long ambiguous words. Our results will not be able to address the issues of timing, given the low temporal resolution of fMRI, but they will be able to address the issue of localization. Thus, for both types of figurative language, we will compare the distribution of activations with metaphoric and ironic statements to that found for literal statements, but we will not be able to discern differential effects of context.

Although most models posit that irony and metaphor are similar in some respects, there are also important differences between the two non-literal forms. Sperber and Wilson (1995) have proposed that metaphor is a descriptive use of language that involves a relationship between the propositional form of an utterance and the thought that it is representing. Irony is more interpretive and complex, in that it involves a relationship between the thoughts of the speaker and the thoughts of someone else (e.g., by alluding to the failure of shared expectations or the violation of norms, as proposed by Kumon-Nakamura, Glucksberg, \& Brown, 1995). One source of empirical evidence for the differences between irony and metaphor is found in developmental studies of normal children. These studies have found that metaphors are comprehended at an earlier age than ironies (Bara \& Bucciarelli, 1998; Happe, 1993; Winner, 1988). Apparently, the comprehension of irony is related to the sophistication of theory-of-mind mechanisms, because children and adults who are able to make correct attributions of first order false beliefs (to model what another person knows) are able to comprehend metaphors, but not ironic statements. Children and adults who are able to make correct second order attributions (to model what another person knows about what a third person knows) are able to comprehend ironic statements (Winner, Brownell, Happe, Blum, \& Pincus, 1998). This relative difficulty of irony over metaphor persists over time, as Colston and Gibbs (2002) have shown that it takes healthy adults longer to read ironic than metaphoric statements.

\subsection{Neuropsychological models}

Neuropsychological models of the comprehension of nonliteral language are based on data from a variety of paradigms. The classic studies indicate that an intact RH is necessary for efficient processing of metaphors and connotations (Brownell, Potter, Meichelow, \& Gardner, 1984; Brownell, Simpson, Bihrle, Potter, \& Gardner, 1990; Winner \& Gardner, 1977). More recent studies using tasks involving different discourse processes have revealed dissociations in populations with brain damage, where irony comprehension may be deficient, but metaphors are comprehended relatively better, or vice versa, in different patients (Langdon, Davies, \& Coltheart, 2002). There is some relation between lesion locus and comprehension deficit (right hemisphere lesions impair irony comprehension more than metaphor comprehension; left hemisphere lesions impair metaphor comprehension more than irony comprehension (Giora, Zaidel, Soroker, Batori, \& Kasher, 2000; McDonald, 2000)), supporting the hypothesis that there may be distinguishable brain substrates associated with such processing. However, a clear-cut consistent specialization of the $\mathrm{RH}$ for the processing of figurative language with unilaterally 
brain-damaged patients has not been found (e.g. Klepousniotou \& Baum, 2005; Tompkins, 1990). Importantly, recent studies of the pragmatic abilities of patients with agenesis of the corpus callosum have shown that although they have intact right and left hemispheres, and are able to transfer semantic information (probably via the anterior commissure), as shown in intact Stroop interference, they are deficient in the comprehension of both emotional prosody and conventional metaphors (Paul, Van Lancker-Sidtis, Schieffer, Dietrich, \& Brown, 2003). Given the relationship between emotional processing and irony comprehension, and the fact that these participants made no errors on literal phrases, these authors suggested that interhemispheric integration of higher order processes is necessary for the processing of non-literal language.

The hypothesis that the RH is involved in 'coarse' semantic coding (Beeman, 1998) and in the processing of alternative meanings of ambiguous words has been examined using divided visual field paradigms with normal participants. These studies have suggested that the RH is less efficient than the LH at suppressing the inappropriate meaning of an ambiguous word (Faust $\&$ Gernsbacher, 1996), and seems insensitive to dominance, frequency, and context in the process of lexical access (Coney \& Evans, 2000; Faust \& Chiarello, 1998). However, specific RH sensitivity to the metaphoric meanings of words with this paradigm has had an uneven history of replication (Anaki, Faust, \& Kravetz, 1998; Faust \& Weisper, 2000).

Thus, behavioral studies with patients and intact participants have suggested that damage in both hemispheres can give rise to deficits in the processing of figurative language, and that higher order interhemispheric integration may be necessary for these processes. The growing number of functional imaging studies of language processing support such a conclusion (see Bookheimer, 2002 for a review). Specifically, many studies have revealed $\mathrm{RH}$ activations in $\mathrm{fMRI}$ studies while participants have been doing many linguistic tasks. RH activations are most often seen when participants must make causal inferences or discourse level computations (e.g. Bottini et al., 1994; Caplan \& Dapretto, 2001; Ferstl \& von Cramon, 2001; St. George, Kutas, Martinez, $\&$ Sereno, 1999).

In sum, there is a large amount of behavioral evidence from normal and brain-damaged populations to indicate that ironic, metaphoric, and literal statements are processed differently. However, the functional organization of these processes is unclear. Our study compared brain activation in the condition where individuals were reading statements in which it was clear that the speaker literally meant what they said versus conditions in which it was clear that they were speaking either metaphorically or ironically. The metaphors that were presented were all conventional or 'frozen' metaphors that were not ironic. For example, given the context: John bragged to Amy that he could run very fast. They had a race and he left her far behind. The metaphoric statement that follows this excerpt is appropriate to the context: Amy said, "You are like greased lightning". In addition, all of the ironies were non-metaphoric. That is, the character always said the opposite of what they meant. Thus, consider the context, George promised to be quiet in the library. He got in trouble for talking very loudly. The ironic statement that follows contradicts the context: His dad said, "Thanks for keeping your promise". The underlined statements were being read during the fMRI data acquisition. The full list of stimuli is in the appendix. We expected to see the effects of the common mechanisms in the comprehension of these three types of statements, which should evoke the classical language areas in the left hemisphere, together with differences, either in the pattern of left hemisphere activation, or in right hemisphere participation, resulting from the distinguishing processes for metaphor and irony. The more general goal was to use the discovery of the neural bases of these discourse processes to enrich the psychological characterization of the figurative comprehension processes.

\section{Methods}

Participants read brief stories ending in either a literal, metaphoric, or ironic statement. We used fMRI in an event related design to measure brain activation while the participants were reading the final, critical sentence.

\subsection{Participants}

The participants were 16 right-handed students ( 7 female) at CarnegieMellon University who were paid for their participation and signed IRBapproved informed consent forms.

\subsection{Materials}

The stories consisted of three sentences. The first two sentences constituted the context for the third sentence, which was always a literal, ironic, or metaphoric statement made by one of the characters in the story. The final sentence was followed by a simple yes/no comprehension question, to ensure that they were attending to the content of the stories. There were 9 stories of each type, with the 27 stories presented in a random order. Two versions of the stimulus materials were used (differing slightly to fit different types of final statements) so that type of final statement was not confounded with the story content. In a separate norming study, 20 participants who were not in the imaging experiment read the stories and classified the final statements as literal, metaphorical, ironic, or other. Half of these norming participants read Version 1 and half read Version 2. For Version 1, 94\% (for literal statements), 93\% (for metaphoric statements), and $96 \%$ (for ironic statements) of the participants agreed with our classification. For Version 2, 88\%, $87 \%$ and $88 \%$ agreed with our classification respectively, for literal, metaphoric, and ironic statements. Both versions are listed in the appendix, together with the proportion of participants who classified the statement according to our categories.

A comprehension question followed each of the stories (see below), which asked about the true state of beliefs of the speaker. For example, in the story about the race between John and Amy, the question was: 'Does Amy think John runs faster than her?', and the participant had to press a button for 'yes' or 'no'. Thus, we insured that the participants understood what the speaker really thought, even if their utterance was metaphoric or ironic (e.g., the opposite of what they really thought). It may be argued that we cannot know that our participants processed the metaphoric statements, but given that these were healthy university students, and that the metaphors were all familiar ones, and that the pretest was done on the same population, we feel confident that the critical figurative statements were understood as such.

\subsection{Procedure}

The first two sentences of each story were presented together for $5 \mathrm{~s}$, followed by a $3 \mathrm{~s}$ blank period. The third, critical sentence appeared next for $5 \mathrm{~s}$, followed by a $7 \mathrm{~s}$ blank period. Finally, a $4 \mathrm{~s}$ period containing the comprehension probe question followed. Fig. 1 shows the timings of the story presentation. Five $20 \mathrm{~s}$ fixation periods were interspersed among the stories, one at the beginning, and then every seven stories. These fixation presentations were used as baseline activation levels for the computations described below. Stories that were not followed by a $20 \mathrm{~s}$ fixation period were instead followed by a $7 \mathrm{~s}$ rest period. Only 


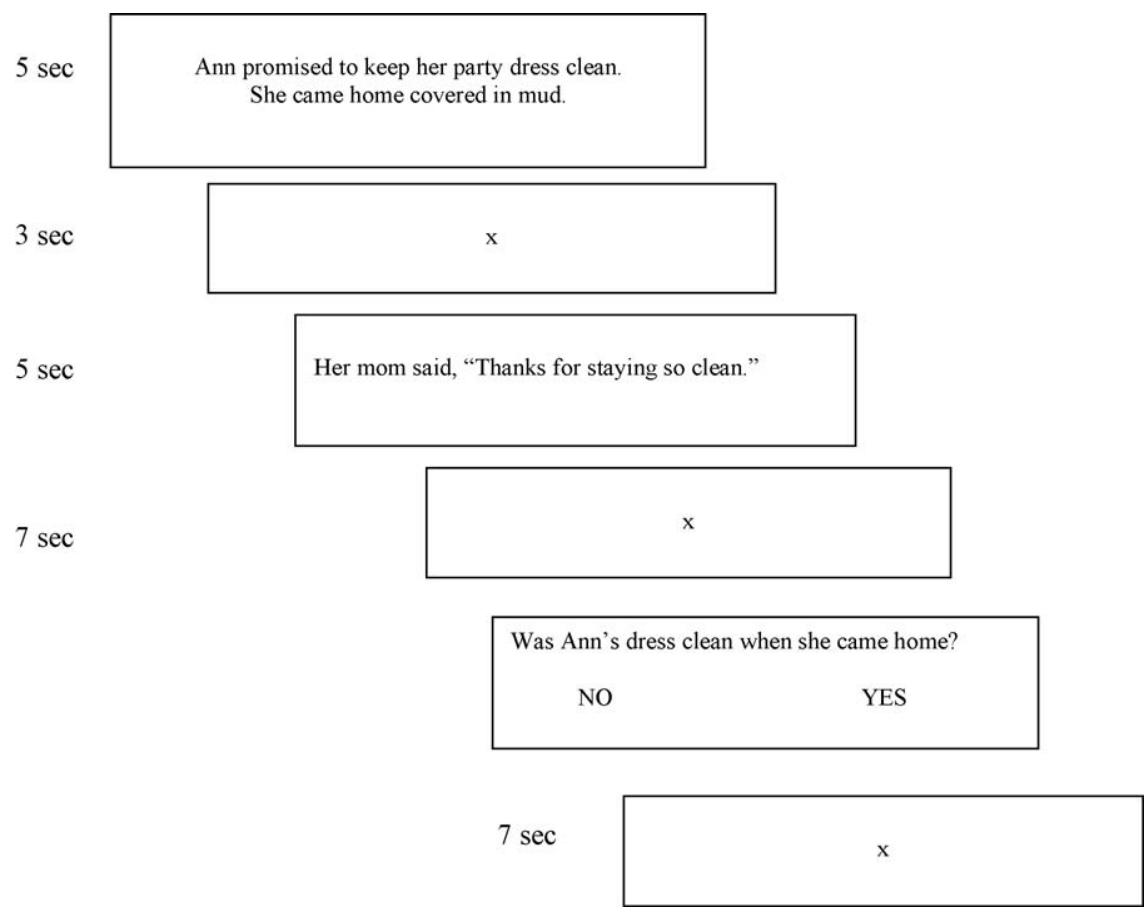

Fig. 1. Stimulus presentation timing in single trial.

items in which the participant answered the question correctly were included (no participant made more than two errors). Approximately a day or two before scanning, the participants were familiarized with the task using different stimulus materials.

\subsection{Imaging procedures}

The fMRI data were collected using a GE Medical Systems 3.0T scanner at the Magnetic Resonance Research Center of the University of Pittsburgh Medical Center. A commercial birdcage, quadrature-drive radio-frequency whole head coil was used. The study was performed with a gradient echo, resonant echo planar pulse sequence with $\mathrm{TR}=1000 \mathrm{~ms}, \mathrm{TE}=18 \mathrm{~ms}$ and a $70^{\circ}$ flip angle. Sixteen oblique-axial slices were imaged, and each slice was $3 \mathrm{~mm}$ thick with a gap of $1 \mathrm{~mm}$ between slices. The acquisition matrix was $128 \times 64$ with $3.125 \mathrm{~mm} \times 3.125 \mathrm{~mm} \times 3 \mathrm{~mm}$ voxels. Structural images for anatomic localization were taken in the axial plane and then resliced to correspond to the functional images. They were a 124-slice SPGR volume scan with TR $=25 \mathrm{~ms}$, $\mathrm{TE}=4 \mathrm{~ms}$. The acquisition matrix was $256 \times 256$, with $1.5 \mathrm{~mm}$ slice thickness. Image preprocessing (including baseline correction, de-ghosting, mean correction, motion correction, and trend correction) was performed using FIASCO (Eddy, Fitzgerald, Genovese, Mockus, \& Noll, 1996; Lazar, Eddy, Genovese, $\&$ Welling, 2001). The mean of the maximum head motion for each participant did not exceed .3 voxels. Participants whose data exceeded this criterion were excluded.

\section{5. fMRI analyses}

To compare the amount of activation in each participating cortical area across conditions, 19 anatomically defined ROIs were drawn for each participant using the parcellation scheme described by Rademacher, Galaburda, Kennedy, Filipek, and Caviness (1992) and further refined by Caviness, Meyer, Makris, and Kennedy (1996), as shown in Fig. 2. These ROIs are intended to include any cognitively related areas in which at least some participants produced activation. The ROIs were defined independently by two highly trained staff members (with an inter-rater reliability of .84 in previous studies) for each individual participant and any discrepancies were systematically resolved. The use of a priori defined anatomical ROIs allows the activation volume to be assessed within each participant's native brain space without any morphing-induced distortion (Nieto-
Castanon, Ghosh, Tourville, \& Guenther, 2003), and the resulting assessment in each ROI can be averaged over participants and compared across conditions.

The central fMRI data for each item came from 5 images obtained for $5 \mathrm{~s}$ (at a rate of 1 image per sec), starting from $6 \mathrm{~s}$ after the exposure of the critical statement, to allow for the hemodynamic response delay (Bandettini, Wong, Hinks, Tokofsky, \& Hyde, 1992). There were nine such intervals (1 per story) in each experimental condition, resulting in 45 images per condition per participant. These were compared to the 100 images per participant obtained during the five $20 \mathrm{~s}$ fixation intervals, which constituted our baseline measures. The data analysis quantified BOLD-contrast-related changes in the fMRI-measured signal using a dependent measure which takes into account both the volume of activation and the percentage change in signal relative to a fixation baseline level (Xiong, Rao, Gao, Woldorff, \& Fox, 1998). These two dependent measures typically both show effects of cognitive manipulations. For each voxel in the $a$ priori defined ROIs, the intensity of signal in an experimental condition was compared to that for the fixation condition using a $t$-test with a threshold of $t>5.0$, a high threshold that is similar in conservativeness to a Bonferroni correction for multiple comparisons. The sum of the percentage change in signal

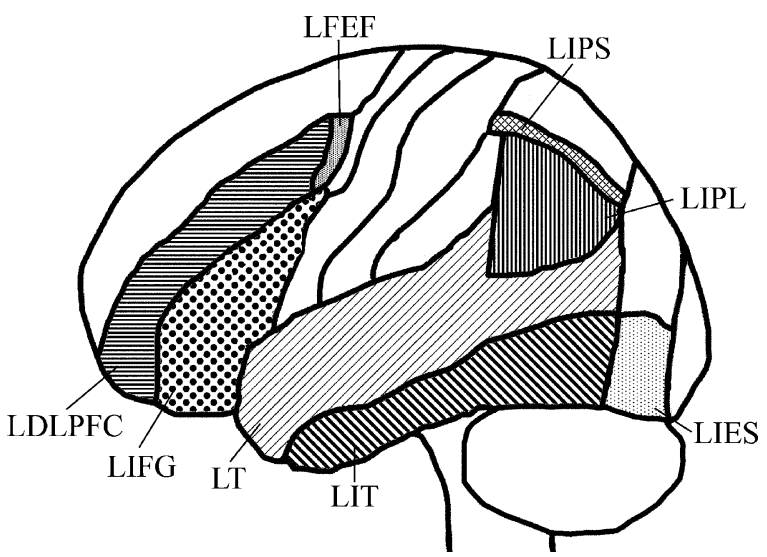

Fig. 2. Schematic of the eight lateralized ROI definitions per hemisphere (adapted from the Caviness et al. (1996) parcellation scheme. The ROI labels are explained in Table 1. 
intensity was then calculated for each ROI and each condition by cumulating the change in signal intensity (relative to the baseline) across voxels that reached the critical threshold for that condition. Thus for each ROI, for each experimental condition, the mean (over 16 participants) sum \% change in signal intensity (and the count of activated voxels) reflected the amount of difference in the BOLD contrast-related changes between that experimental condition and the baseline.

\section{Results}

Within each ROI, a one-way ANOVA tested for the effect of the type of critical utterance (literal, ironic, or metaphoric) on the measure of activation (mean sum signal intensity) across the 16 participants. Six regions of interest across the two hemispheres revealed differential effects of statement type, and therefore subsequent analyses focused on these regions. The results are shown in Table 1, with those areas showing reliable outcomes of planned comparisons highlighted in gray. (The analyses using the number of activated voxels as the dependent variable (these means are shown in parentheses in Table 1) yielded slightly weaker versions of the same patterns as did the analyses using sum signal intensity. Therefore, only the latter are further discussed.)

In three regions in the left hemisphere, the inferior frontal gyrus (IFG), the inferior temporal gyrus (IT), and the inferior extrastriate cortex (IES), the activation for metaphoric statements was significantly greater than for the other types of statements, as shown in Table 1. Planned comparisons were made between the mean $\%$ signal change in the three experimental conditions within each of these regions. The $F$-ratios comparing metaphoric versus literal statements were: in IFG $F(1,15)=7.43, p<.01$; in IT: $F(1,15)=5.84, p<.05$; and in IES: $F(1,15)=7.96, p<.01$. The $F$-ratios comparing metaphoric versus ironic statements were: in $\operatorname{IFG} F(1,15)=4.15, p<.05$; in IT $F(1,15)=4.51, p=.05$; and in $\operatorname{IES} F(1,15)=3.86, p<.06)$. These results are shown in Fig. 3.

Two areas showed reliable effects of statement type in the right hemisphere, as shown in Table 1. The right superior and middle temporal region revealed higher activation levels for ironic statements than for literal statements, $F(1,15)=5.21$, $p<.05$; metaphoric statements resulted in intermediate values. In the right inferior temporal gyrus (RH IT), the effect was the same as the one in the left inferior temporal gyrus ( $\mathrm{LH}$ IT), but much smaller in magnitude. Although levels of activation are attenuated in the RH (a reflection of left hemispheric specialization for this linguistic task), the activation levels for metaphors are significantly higher than for the other types of statements (metaphoric versus literal statements: $F(1,15)=5.23$,

Table 1

Mean sum \% change in signal intensity (and number of activated voxels) and Talairach coordinates of activation in each ROI condition

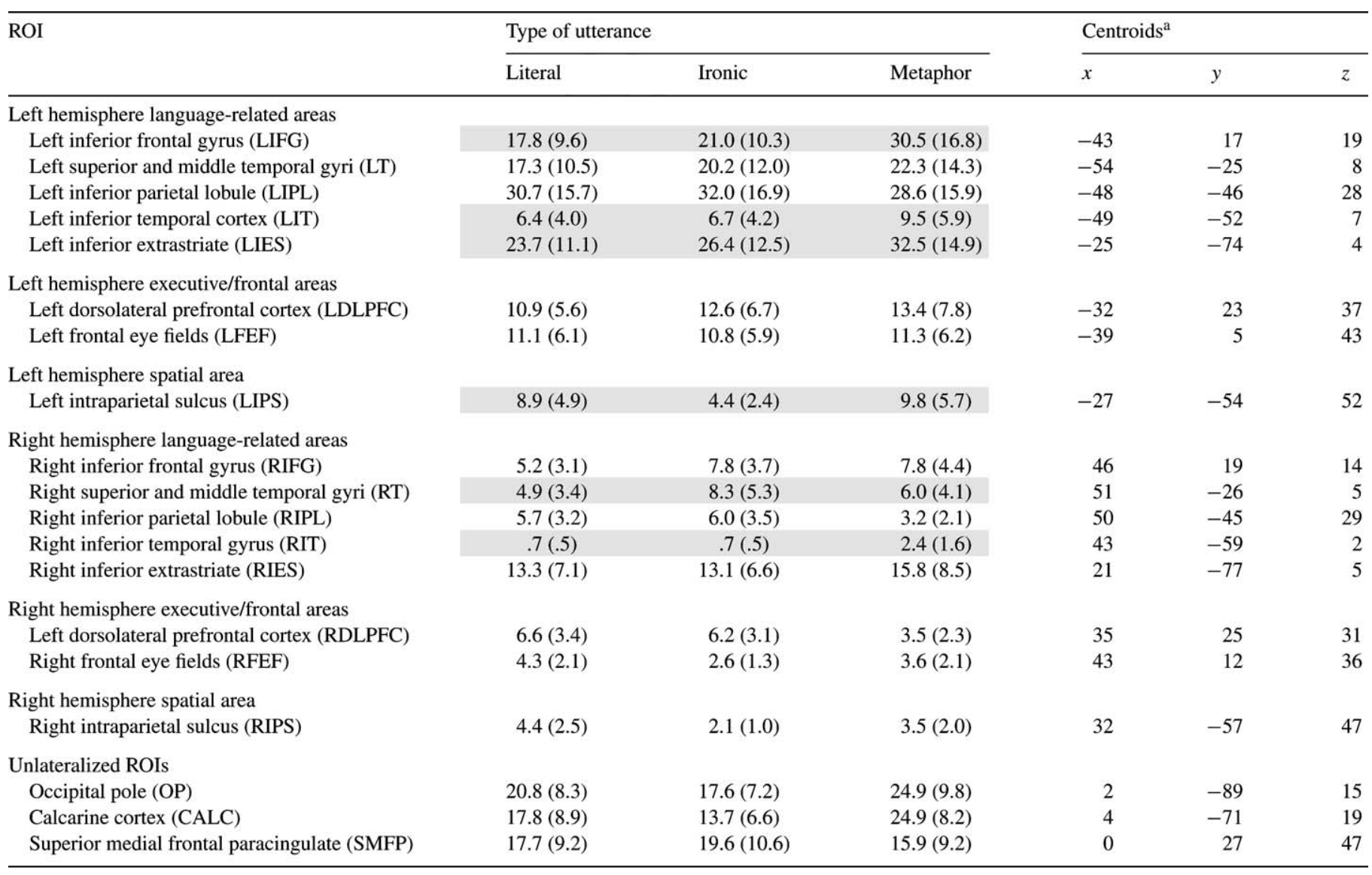

The regions containing significantly different amounts of activation are shaded.

${ }^{a}$ Centroids (centers of mass) of activation in each ROI are group averages of individual participants' centroids which were morphed into Talairach space. The centroids are presented for only the metaphor condition because they were similar in the other conditions. 

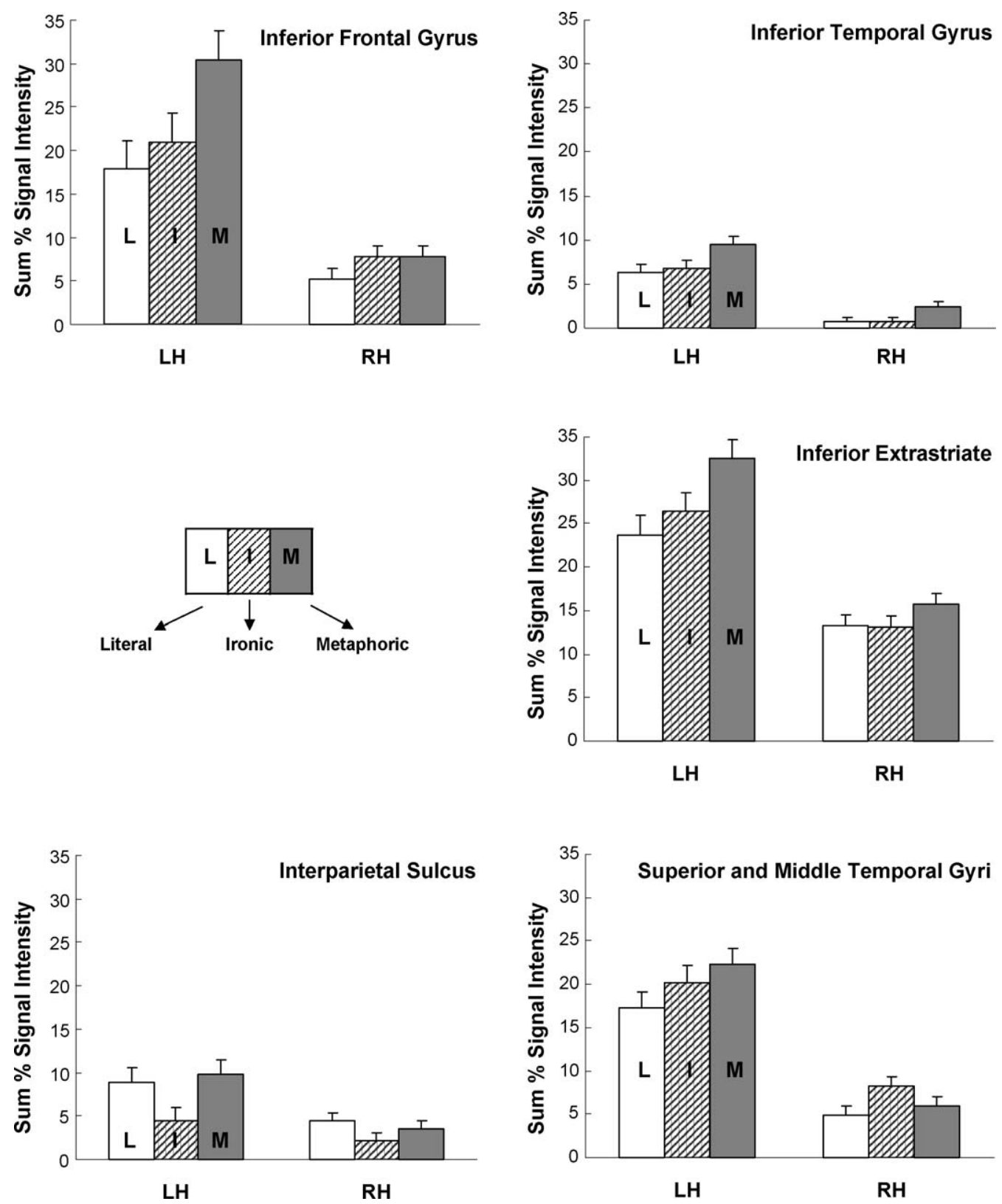

Fig. 3. Five brain regions showing differential effects of the type of critical utterance in the sum of $\%$ signal intensity. The upper three graphs show differential effects of metaphoric statements vs. literal and ironic statements. The graphs in the bottom row show differential effects of ironic statements vs. literal and metaphoric statements. The error bars are based on the mean S.E. derived from the ANOVAs.

$p<.05$; metaphoric versus ironic statements: $F(1,15)=5.29$, $p<.05)$.

Another left hemisphere area, the intraparietal sulcus (IPS), showed higher activation for metaphor than for irony, but the literal statements produced an intermediate level of activation. It may be that metaphoric and literal interpretation both entail some degree of visual imagery, resulting in IPS activity during sentence comprehension (Just, Newman, Keller, McEleney, \& Carpenter, 2004). By contrast, irony may be more of a semantic/logical mode than a visual transformation, hence there would be less IPS activity. Fig. 4 illustrates all of these patterns in the surface rendering of the group activation, as well as in one axial slice.

\section{Discussion}

We have shown that the three types of statements all resulted in activation of the classical language areas in the LH, indicating consistency with previous imaging studies of language comprehension. At the same time, metaphoric statements resulted in significantly higher activation levels than ironic and literal statements in three of the regions, the left inferior frontal gyrus, the left inferior temporal gyrus, and the left inferior extrastriate region. Two different areas in the right temporal lobe were differentially sensitive to irony and metaphor: ironic statements resulted in differential activation levels in the right superior and middle temporal gyri, while metaphoric statements resulted in 
(a)
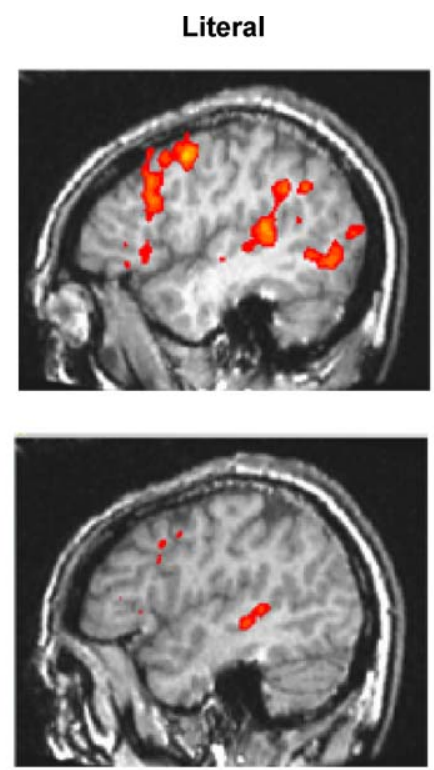

(b)

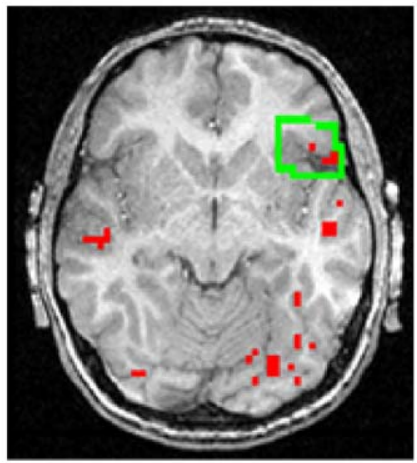

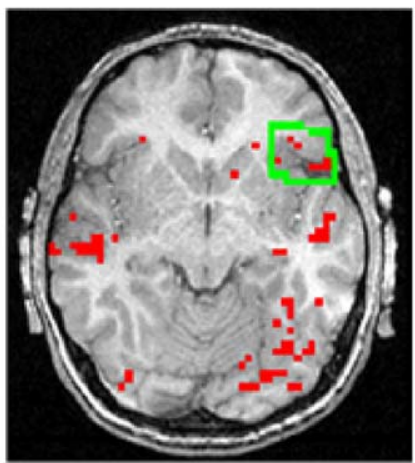

Ironic
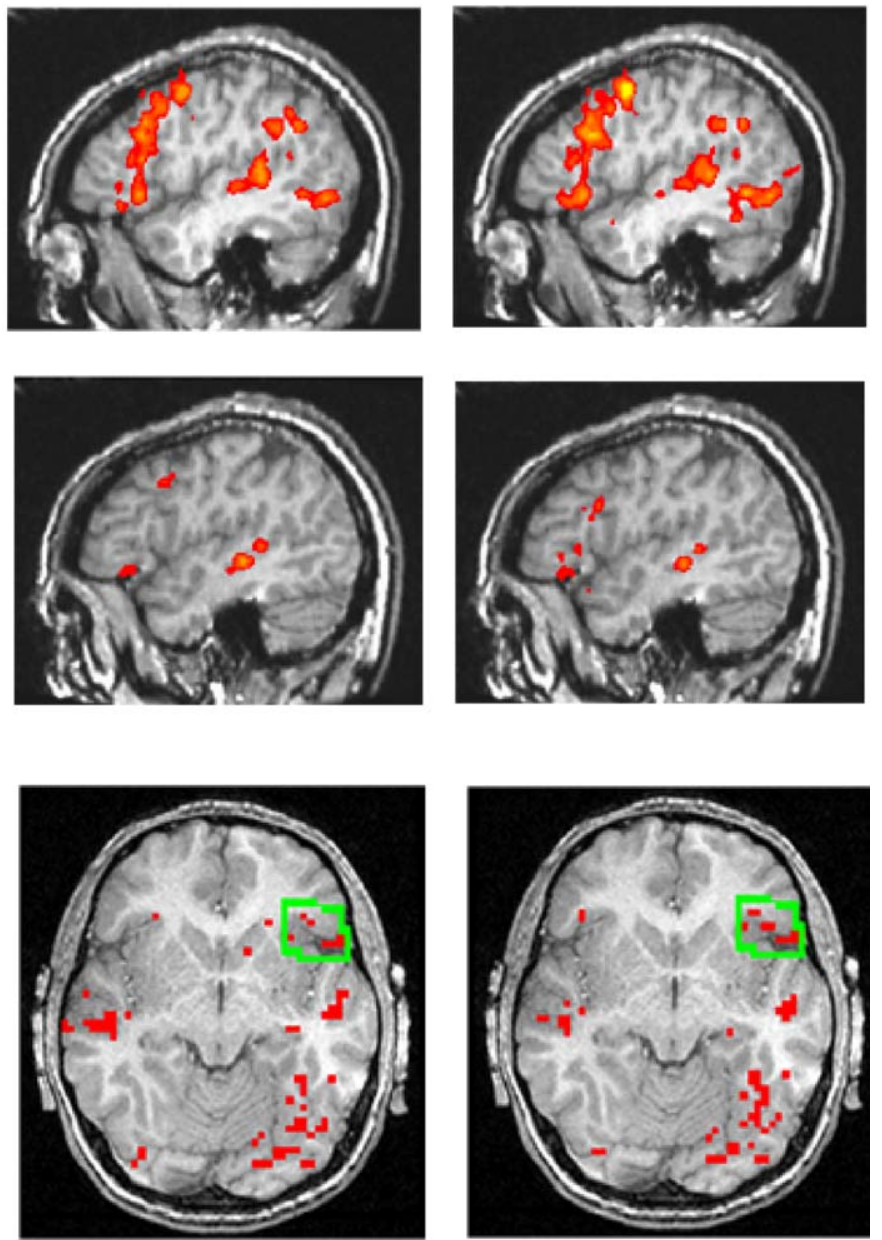

$\mathbf{R}$

L

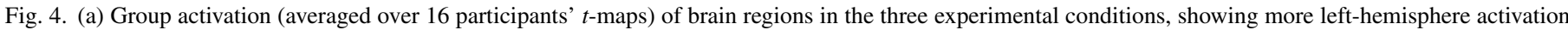

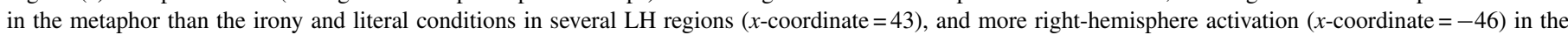

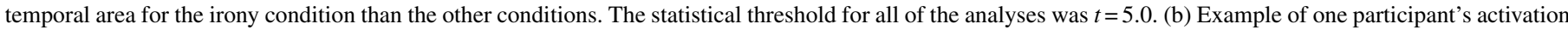
in left IFG in each of the three experimental conditions.

relatively higher activation levels in the inferior temporal gyrus. These results support the position that figurative language is processed by the same general mechanism as literal statements, but also that irony and metaphor processing have distinguishing characteristics.

\subsection{Metaphor}

The finding of higher activations in the left IFG and inferior temporal regions for metaphors replicates the finding reported by Rapp et al. (2004), and converges with hypotheses that this area is involved in semantic selection (e.g. Keller, Carpenter, \& Just, 2001). Variations of models of metaphor comprehension usually involve some kind of comparison between the subject of the metaphor and the vehicle, which is done by selection of the salient features of the vehicle to be compared to the subject (that is, Mary is as sharp as a razor because being smart is like being sharp (Glucksberg, 1998)). Another type of model suggests that the relations between the subject and the vehicle are categorical (Glucksberg \& Keysar, 1990), such that the subject becomes a member of a transient category exemplified by the vehicle (Mary is a sharp razor). In both types of models, the meanings of frequently used metaphors (such as the ones used in this study) are lexicalized. The lexical contents of the phrase 'sharp as a razor' includes, in addition to the literal meaning, the more abstract meaning of 'smartness'. Thus, the comprehension of these metaphors relies on lexical selection processes, which are subserved at least in part by the left IFG (Keller et al., 2001).

The new results bear a sensible relation to two previous imaging studies of metaphor processing, Bottini et al. (1994) and Rapp et al. (2004). Both of these previous studies used novel metaphors, whereas we used conventional, or idiomatic metaphors. Bottini et al. asked participants to judge whether the metaphors were plausible or not, and Rapp et al. asked their participants to judge whether their metaphors had a positive or negative connotation. Interestingly, Bottini et al. found differential RH activation for metaphor processing in inferior frontal gyrus, middle temporal gyrus, and precuneous, whereas Rapp 
et al. found higher activation for metaphoric versus literal sentences in the same areas that we did: LH inferior frontal gyrus and inferior temporal gyrus. It is important to examine the similarities and differences between the three studies in our evaluation of the results. The differences are at many levels. Bottini et al. used PET imaging and a block design, while Rapp et al. and the present study both used fMRI and an event-related design. It may be that these procedural differences underlie some of the differences among the results. However, the most important difference is that both previous studies used novel metaphors, whereas we used conventional metaphors.

Several theorists (e.g. Giora, 1999) have suggested that novel and conventional metaphors are processed differently, and some of our own research in progress strongly confirms this proposal. Specifically, the suggestion has been that novel metaphors require computation of the relations between the vehicle and the subject of the metaphor, whereas conventional metaphors are lexicalized, and are actually like long words, whose meaning is accessed as a unit. Thus, one would expect that the previous two studies would pattern together. In explaining the differences between their study and that of Bottini et al., Rapp et al. suggested several sources of difference, other than the technology (PET versus fMRI) and design. Specifically, they suggest that the task, judging the plausibility of the metaphors, together with the higher complexity of stimuli, resulted in the recruitment of $\mathrm{RH}$ resources in the Bottini et al. study and not in theirs. This is because although the task in their study, judging whether the metaphor has a positive or a negative connotation, required semantic processing, it was independent of the lexical relationship of the nouns within the sentence. In the Bottini et al. study, implausible metaphors violated the semantic properties of the head nouns, e.g., 'the investors were trams'. In our study, the stimuli were complex, in that they were stories. However, all of the metaphors were both apt and conventional, such that they were plausible in the context of the stories. Thus, it may be that the critical difference between the study that found $\mathrm{RH}$ involvement in metaphor comprehension and the two studies that did not, is the necessity to evaluate the context of metaphor. That is, when the task involves lexical access of the words in the sentence, as with the simple metaphors of Rapp et al., or with our lexicalized metaphors, we see LH activations, and when it requires a higher level of analysis, as in a plausibility decision, we see recruitment of RH regions.

There may be more than one reason that $\mathrm{RH}$ regions are activated during the processing of novel metaphors. Because we did not study such metaphors, we have no new data to offer here. However, one possibility is that $\mathrm{RH}$ regions are recruited when the task is made more difficult, by requiring the participants to make some sort of metalinguistic judgment about the stimuli. For example, Sotillo et al. (2005) reported ERP generators of the N400 in a novel metaphor comprehension task in the right superior temporal gyrus, but the task also required participants to judged if a following word was related to the metaphor. The classic neuropsychological patient studies that found deficits in metaphoric processing in RH damaged patients relative to $\mathrm{LH}$ damaged patients also required high-level judgments in addition to the comprehension, such as judging the suitability of a visual representation of a metaphor (Winner \& Gardner, 1977), or grouping pairs of words according to perceived similarity (Brownell et al., 1984, 1990). Another possible reason for RH activation during novel metaphor comprehension is that qualitatively different processes are recruited, possibly involving a search through coarse-coded information. Both accounts are also supported by the findings of Kuperberg et al. (2000), who found that sentences that violated semantic restrictions (e.g., the semantic properties of the verb were incompatible with the semantic properties of the object noun- the young man drank the guitar') resulted in higher activation in the right superior and middle temporal gyri, whereas sentences in which the violation was syntactic (the young man slept the guitar) did not. Regardless of the role of the $\mathrm{RH}$ in novel metaphor comprehension, these previous results are all consistent with the contention that the left IFG and temporal regions are involved in lexical access, and that conventional metaphors such as ours are accessed as lexical items.

We also saw that the inferior temporal gyrus in the right hemisphere showed the same pattern as the inferior temporal gyrus in the left hemisphere. These data suggest that $\mathrm{RH}$ temporal regions are recruited when plausibility is computed, semantic judgments are made, or more generally, as we show below, when the structure of the whole narrative is processed, when the discourse is ironic.

\subsection{Irony}

Our results support the hypothesis that the RH is differentially involved in the comprehension of irony. More specifically, it may be that the processing of irony can be related to the processing of communicative intent or the construction of a coherent narrative. The literal interpretation of an ironic utterance makes no sense in its context. The involvement of the RH in the comprehension of narratives has been suggested by patient studies, and may be related to the ability of the participants to understand the speaker's communicative intent (in the terms of relevance theory (Sperber \& Wilson, 1995)) as dissociated from their informative intent. In the literal and metaphoric conditions of our study there was no such dissociation: if the hearer could correctly categorize the subject of the metaphor as a member of the category defined by the vehicle (as in Glucksberg's (1998) model), then they knew that the speaker meant what they said. In the ironic condition however, it had to be clear that the speaker was 'pretending' - that is, not meaning what they said. This could be computed by processing the coherence of the critical utterance in the context of the whole story. Robertson et al. (2000) reported higher levels of fMRI activation in the right middle temporal gyrus in an fMRI study in which participants read series of unconnected sentences that they formed into narratives. Beeman et al. (2000) showed that predictive inferences are activated in the $\mathrm{RH}$, and suggested that this is a reflection of coarse semantic coding in the $\mathrm{RH}$. These findings together converge to suggest recruitment of $\mathrm{RH}$ regions, when discourse processing requires construction of relations between separated entities in the utterance, to make inferences or to compute plausibility or coherence. 
A number of imaging studies have suggested that medial frontal regions, particularly the paracingulate gyrus, are activated when participants are performing tasks that rely on Theory of Mind processing (see Gallagher \& Frith, 2003 for a review). As the bottom of Table 1 indicates, activation in this area (SMFP, for superior medial frontal paracingulate) was high for all three types of utterances, and was not sensitive to utterance type. This area has been proposed to subserve the process in which ' . . cues are used in a particular way; that is, to determine an agent's mental state, such as a belief, that is decoupled from reality, and to handle, simultaneously these two perspectives of the world' (Gallagher \& Frith, 2003, p.79). It may be the case that because all of the stories were followed by a question about the true situation (e.g., was Ann's dress clean or not, see Fig. 1), participants computed the mental state of the characters in all of the stories.

\section{Conclusions}

Our results converge with reports of the performance of participants with unilateral brain damage on tests of sarcasm and metaphor comprehension. Giora et al. (2000) reported that patients with unilateral brain damage in the RH achieved lower scores than patients with unilateral LH damage on a test of sarcasm comprehension, and higher scores than patients with unilateral LH damage on a test of metaphor comprehension. Thus, the RH is differentially implicated in irony comprehension, and the LH is differentially implicated in metaphor comprehension. However, we also showed activation patterns in different regions of the right temporal lobe, for ironic and metaphoric utterances, supporting the hypothesis that within the $\mathrm{RH}$, these two types of statements require the recruitment of different areas.

Our findings converge with a large number of results of functional neuroimaging studies that support a view of brain function in networks of brain regions that work together to constitute the functional architecture of the mind. Specifically, as shown in Fig. 4a, all of our stimuli activated the classical perisylvian language regions. However, both ironic and metaphoric statements resulted in extra activation in addition to this basic pattern: ironic statements resulted in the addition of a RH temporal region, and metaphoric statements resulted in a larger volume in left IFG being activated above threshold. Just, Carpenter, Keller, Eddy, and Thulborn (1996) proposed that functional networks of brain regions that function together to subserve a cognitive process are dynamic, such that added complexity in the cognitive process results in the conscription of additional brain areas to the networks. The results of the present experiment reveal that the type of complexity (irony or metaphoric language) affects the location of brain regions that are added to the network.

It may be surprising from some perspectives to find that there was not more activation in RH than LH for both irony and metaphor processing. Although processing of both types of figurative language has been characterized as a RH function, it is more likely that it is a bilateral function, with asymmetry in the amount of activation in the two hemispheres. The degree of this asymmetry itself is likely subject to modulation by the characteristics of the comprehension task. In general, fMRI studies are repeatedly demonstrating that laterality of activation is a dynamically determined property of the processing in the task, as are many other aspects of activation. Which factors dynamically determine the degree of laterality in activation and in control of processing in specific tasks is an extremely interesting set of issues for future research.

\section{Acknowledgements}

This work was partly supported by the National Institute of Mental Health, Grant MH-29617. We thank Rachel Giora for comments on an earlier draft of the paper.

\section{Appendix A}

Stimuli used in the experiment. Half the participants saw Version 1 and half saw Version 2. Preliminary analyses revealed no differences between the versions, such that the results were pooled across version. The numbers next to each question are the percentage of participants in the norming study who classified it as we did. Items in bold type were being read in the imaged interval.

Version 1

Literal items

Johnny went on a hike with his brother. Suddenly he saw a huge snake next to his foot

He said, "I am so scared"

Jim cleaned the backyard all day. He didn't take any breaks

Mother said, "Jim, maybe you should eat something"

Joe's little brother fell and hurt his knee. Joe washed it and put a band-aid on it

His brother said, "You are so nice to me"

Betsy and Mary were on the basketball team. Mary scored a lot of points in the game

Betsy said, "Mary is a great player"

Jack was talking on the phone. Sally and Mary came in very quietly

Jack said, "I didn't notice you were here"

Betty and Laura were in the same class. Laura finished her homework before Betty

Laura said, "You sure are a slow worker"

Harry waited in line for $3 \mathrm{~h}$ to see the movie. He enjoyed himself

He said, "That was worth waiting for"

Ms. Jones asked the class to be very quiet. They got a prize for being the best-behaved class

She said, "Thanks for listening to me"

Jim beat everyone in the class in chess. Harry introduced Jim to the new teacher

He said, "Jim is our best chess player"

Metaphoric items

In the morning John came to work early. He started to work right away at a fast pace

His boss said, "John is a hurricane"

Father asked Mary to help him set the table. She sang a song as she put all the plates in their places

Father said, "You are my sunshine"

Mary got straight A's on her report card. Her parents were proud of her 
They said, "You are as sharp as a razor"

Susie helped her mom when her brother got sick. She took good care of him

Her mom said, "You are an angel from heaven"

Tom and Mike planned to go on a picnic. In the morning the sun was shining

Tom said, "It's a golden day"

Larry told Sally that he knew how to cook. He gave her a taste of his wonderful stew

Sally said, "This is heaven"

Lilly enjoyed herself at the movies. Jane asked her about the movie

Lilly said, "I laughed my head off"

Donna was always late for everything. Today she made it home on time for supper

Her dad said, "You have turned over a new leaf"

Laura was out sick for a week. Johnny called her every day

Laura said, "You are a mother hen"

Ironic items

Jane hates eggplant. Her mother prepared a big eggplant salad for supper

Jane said, "Oh wow, my favorite food"

George went to Betty's birthday party. Only two other people came

He said, "It is really crowded here"

Tommy worked hard in the garden. His brother threw leaves at him

Tommy said, "Thanks for all your help"

Ken was worried about having his hair cut. When the barber finished, Ken looked terrible

He said, "Thanks for the great haircut"

John bragged that he could run faster than Amy. They had a race and she left him far behind

She said, "You sure are faster than me"

Ann promised to keep her party dress clean. She came home covered in mud

Her mom said, "Thanks for staying so clean"

George promised to be quiet in the library. He got in trouble for talking very loudly

His dad said, "Thanks for keeping your promise"

At the restaurant Mark said he wasn't hungry. He ordered only coffee and ate all of Ed's fries

Ed said, "I can see you're not hungry"

Mary fell asleep during the movie. John woke her up at the end

She said, "It was just too exciting for me"

Version 2

Literal items

Jane loves chicken. Her mother prepared roast chicken for supper

Jane said, "Oh wow, my favorite food"

Father asked Mary to help him set the table. She sang a song as she put all the plates and silverware in their places

Father said, "You are really helping me"

Mary got straight A's on her report card. Her parents were proud of her

They said, "What a smart girl you are!"

Tommy worked hard in the garden. His brother came and raked the leaves

Tommy said, "Thanks for all your help"

Susie helped her mom when her brother got sick. She took good care of him

Her mom said, "You deserve a prize"

George promised to be quiet in the library. He sat in a corner looking at a book
100\% His dad said, "Thanks for keeping your promise"

Donna was always late. Her parents bought her a new watch, and she was on time for supper

90\% Her dad said, "I'm glad we got you a watch"

Mary couldn't sleep after seeing the movie. She told John about it

90\% She said, "It was just too exciting for me"

Laura was out sick for a week. Johnny called her every day

Laura said, "Thanks for worrying about me"

$100 \%$

Metaphoric items

George went to Betty's birthday party. Fifty people crowded into her small apartment

$90 \%$

He said, "I feel like a sardine"

Jim ate a big lunch with three desserts. When he finished he asked for more

$90 \%$

$90 \%$

Mom said, "Jim, you are a bottomless pit"

Jack was talking on the phone. Sally and Mary came in very quietly

Jack said, "You are as quiet as mice"

Betty and Laura were in the same class. Laura finished her homework before Betty

$100 \%$

Laura said, "You work like a snail"

Ken was worried about having his hair cut. When the barber finished, Ken's ears stuck out

$100 \%$ He said, "You've turned me into a clown"

John bragged to Amy that he could run faster than Amy. They had a race and he left her far behind

Amy said, "You are like greased lightning"

Ann promised to keep her party dress clean. She came home covered in mud

$100 \% \quad$ Her mom said, "You are a dirt magnet"

At the restaurant Mark said he wasn't hungry. He ordered only coffee and ate all of Ed's fries

Ed said, "You're like a vacuum cleaner"

Ms. Jones asked the class to be very quiet. The principal yelled at them for making noise

She said, "I feel like I'm talking to the walls"

$80 \%$

Ironic items

$100 \%$

Johnny's little sister was mad at him. When she tried to hit him Johnny laughed at her

He said, "I am so scared"

In the morning John came to work late. He immediately decided to take a break

His boss said, "Don't work so hard"

$90 \%$

Joe's little brother fell and hurt his knee. Joe laughed and didn't help him get up

His brother said, "You are so nice to me"

Betsy and Mary were on the basketball team. They lost the game when Mary missed all her shots

Betsy said, "Mary is a great player"

Tom and Mike planned to go on a picnic. In the morning it was raining very hard

80\% Tom said, "Great weather for a picnic"

Larry told Sally that he knew how to cook. When she tasted his watery stew, it was awful

90\% Sally said, "You sure are a great cook"

Lilly was nervous walking alone at night. Her brother sneaked up and scared her

$100 \%$

Lilly said, "Very funny"

Harry waited in line for $3 \mathrm{~h}$ to see the movie. It was very boring

He said, "That was worth waiting for"

80\%" Jim lost all the chess games he ever played. Harry introduced Jim to the new teacher

Harry said, "Jim is our best chess player" 


\section{References}

Anaki, D., Faust, M., \& Kravetz, S. (1998). Cerebral hemisphere asymmetries in processing lexical metaphors. Neuropsychologia, 36, 353-362.

Bandettini, P. A., Wong, E. C., Hinks, R. S., Tokofsky, R. S., \& Hyde, J. S. (1992). Time course EPI of human brain function during task activation. Magnetic Resonance Medicine, 25, 390-397.

Bara, B., \& Bucciarelli, M. (1998). Language in context: The emergence of pragmatic competence. In A. C. Quellhas \& F. Pereira (Eds.), Cognition in context (pp. 317-344). Lisbon: Instituto Superior de Psicologia Aplicada.

Beeman, M. (1998). Coarse semantic coding and discourse comprehension. In M. Beeman \& C. Chiarello (Eds.), Right hemisphere language comprehension: Perspectives from cognitive neuroscience (pp. 255-284). Mahwah, NJ, US: Lawrence Erlbaum Associates, Publishers.

Beeman, M. J., Bowden, E. M., \& Gernsbacher, M. A. (2000). Right and left hemisphere cooperation for drawing predictive and coherence inferences during normal story comprehension. Brain and Language, 71, 310336.

Bookheimer, S. (2002). Functional MRI of language: New approaches to understanding the cortical organization of semantic processes. Annual Review of Neuroscience, 25, 151-188.

Bottini, R., Corcoran, R., Sterzi, R., Paulesu, E., Schernone, P., Scarpa, P., et al. (1994). The role of the right hemisphere in the interpretation of figurative aspects of language. Brain, 117, 1241-1253.

Brownell, H. H., Potter, H. H., Michelow, D., \& Gardner, H. (1984). Sensitivity to lexical denotation and connotation in brain-damaged patients: A double dissociation? Brain and Language, 22, 253-256.

Brownell, H. H., Simpson, T. L., Bihrle, A. M., Potter, H. H., \& Gardner, H. (1990). Appreciation of metaphoric alternative word meanings by left and right brain-damaged patients. Neuropsychologia, 28, 375-383.

Cacciari, C., \& Glucksberg, S. (1994). Understanding figurative language. In M. A. Gernsbacher (Ed.), Handbook of psycholinguistics (pp. 447-477). San Diego, CA: Academic Press.

Caplan, R., \& Dapretto, M. (2001). Making sense during conversation: An fMRI study. NeuroReport, 12, 3625-3632.

Caviness, V. S., Jr., Meyer, J., Makris, N., \& Kennedy, D. N. (1996). MRbased topographic parcellation of human neocortex: An anatomically specified method with estimates and reliability. Journal of Cognitive Neuroscience, $8,566-587$.

Colston, H. L., \& Gibbs, R. W. (2002). Are irony and metaphor understood differently? Metaphor and Symbol, 17, 57-80.

Coney, J., \& Evans, K. D. (2000). Hemispheric asymmetries in the resolution of lexical ambiguity. Neuropsychologia, 38(3), 272-282.

Eddy, W., Fitzgerald, M., Genovese, C., Mockus, A., \& Noll, D. (1996). Functional imaging analysis software-Computational olio. In Proceedings in computational statistics. Heidelberg: Physica-Verlag, pp. 3949.

Faust, M., \& Chiarello, C. (1998). Sentence context and lexical ambiguity resolution by the two hemispheres. Neuropsychologia, 36(9), 827-835.

Faust, M., \& Weisper, S. (2000). Understanding metaphoric sentences in the two cerebral hemispheres. Brain and Cognition, 43, 186-191.

Faust, M. E., \& Gernsbacher, M. A. (1996). Cerebral mechanisms for suppression of inappropriate information during sentence comprehension. Brain and Language, 53(2), 234-259.

Ferstl, E. C., \& von Cramon, D. Y. (2001). The role of coherence and cohesion in text comprehension: An event related fMRI study. Cognitive Brain Research, 11, 325-340.

Gernsbacher, M. A., Keysar, B., Robertson, R. R., \& Werner, N. K. (2001). The role of suppression and enhancement in understanding metaphors. Journal of Memory and Language, 45, 433-450.

Gernsbacher, M. A., \& Robertson, R. R. (1999). The role of suppression in figurative language comprehension. Journal of Pragmatics, 31, $1619-1630$

Gallagher, H. L., \& Frith, C. D. (2003). Functional imaging of 'theory of mind'. Trends in Cognitive Neuroscience, 7, 77-83.

Gibbs, R. W. (1994). The poetics of mind: Figurative thought, language and understanding. New York: Cambridge University Press.
Gibbs, R. W. (2001). Evaluating contemporary models of figurative language understanding. Metaphor and Symbol, 16, 317-333.

Giora, R. (1997). Understanding figurative and literal language: The graded salience hypothesis. Cognitive Linguistics, 7, 183-206.

Giora, R. (1999). On the priority of salient meanings: Studies of literal and figurative language. Journal of Pragmatics, 31, 919-929.

Giora, R., Zaidel, E., Soroker, N., Batori, G., \& Kasher, A. (2000). Differential effect of right- and left-hemisphere damage on understanding sarcasm and metaphor. Metaphor and Symbol, 15, 63-83.

Glucksberg, S. (1998). Understanding metaphors. Current Directions in Psychological Science, 7, 39-43.

Glucksberg, S., \& Keysar, B. (1990). Understanding metaphorical comparisons: Beyond similarity. Psychological Review, 97, 3-18.

Grice, H. P. (1975). Logic and conversation. In P. Cole \& J. Morgan (Eds.), Speech acts: Syntax and semantics: Vol. 3, (Vol. 3, (pp. 41-58). New York: Academic Press.

Happe, F. G. E. (1993). Communicative competence and theory of mind: A test of relevance theory. Cognition, 48, 101-119.

Just, M. A., Carpenter, P. A., Keller, T. A., Eddy, W. F., \& Thulborn, K. R. (1996). Brain activation modulated by sentence comprehension. Science, 274, 114-116.

Just, M. A., Newman, S. D., Keller, T. A., McEleney, A., \& Carpenter, P. A. (2004). Imagery in sentence comprehension: An fMRI study. NeuroImage, $21,112-124$.

Keller, T. A., Carpenter, P. A., \& Just, M. A. (2001). The neural basis of sentence comprehension: An fMRI examination of syntactic and lexical processing. Cerebral Cortex, 11, 223-237.

Klepousniotou, E., \& Baum, S. R. (2005). Unilateral brain damage effects on processing homonymous and polysemous words. Brain and Language, 93, 308-326.

Kumon-Nakamura, S., Glucksberg, S., \& Brown, M. (1995). How about another piece of pie: The allusional pretense theory of discourse irony. Journal of Experimental Psychology: General, 124, 3-21.

Kuperberg, G. R., McGuire, P. K., Bullmore, E. T., Brammer, M. J., RabeHesketh, S., Write, I. C., et al. (2000). Common and distinct neural substrates for pragmatic, semantic, and syntactic processing of spoken sentences: An fMR study. Journal of Cognitive Neuroscience, 12, 321-341.

Langdon, R., Davies, M., \& Coltheart, M. (2002). Understanding minds and understanding communicated meanings in schizophrenia. Mind and Language, 17, 68-104.

Lazar, N. A., Eddy, W. F., Genovese, C. R., \& Welling, J. S. (2001). Statistical issues in fMRI for brain imaging. International Statistical Review, 69 , $105-127$

Long, D. L., \& Baynes, K. (2002). Discourse representation in the two cerebral hemispheres. Journal of Cognitive Neuroscience, 14, 228-242.

McDonald, S. (2000). Exploring the cognitive basis of right hemisphere pragmatic language disorders. Brain and Language, 75, 82-107.

Nieto-Castanon, A., Ghosh, S., Tourville, J. A., \& Guenther, F. H. (2003). Region of interest based analysis of functional imaging data. NeuroImage, 19, 1303-1316.

Paul, L. K., Van-Lancker-Sidtis, D., Schieffer, B., Dietrich, R., \& Brown, W. S. (2003). Communicative deficits in agenesis of the corpus callosum: Nonliteral language and affective prosody. Brain and Language, 85, 313-324.

Rapp, A. M., Leube, D. T., Erb, M., Grodd, W., \& Kircher, T. T. J. (2004). Neural correlates of metaphor processing. Cognitive Brain Research, 20, 395-402.

Rademacher, J., Galaburda, A. M., Kennedy, D. N., Filipek, P. A., \& Caviness, V. S., Jr. (1992). Human cerebral cortex: Localization, parcellation, and morphometry with magnetic resonance imaging. Journal of Cognitive Neuroscience, 4, 352-374.

Robertson, D. A., Gernsbacher, M. A., Guidotti, S. J., Robertson, R. R., Irwin, W., Mock, B. J., et al. (2000). Functional neuroanatomy of the cognitive process of mapping during discourse comprehension. Psychological Science, 11, 255-260.

Searle, J. (1979). Expression and meaning. Cambridge, England: University Press. 
Sotillo, M., Carretie, L., Hinojosa, J. A., Tapia, M., Mercado, F., LopezMartin, S., et al. (2005). Neural activity associated with metaphor comprehension: Spatial analysis. Neuroscience Letters, 373, 5-9.

Sperber, D., \& Wilson, D. (1995). Relevance: Communication and cognition. Oxford: Blackwell.

St. George, M., Kutas, M., Martinez, A., \& Sereno, M. I. (1999). Semantic integration in reading: Engagement of the right hemisphere during discourse processing. Brain, 122, 1317-1325.

Swinney, D. A. (1979). Lexical access during sentence comprehension: (Re)consideration of context effects. Journal of Verbal Learning and Verbal Behavior, 18, 645-659.

Tompkins, C. A. (1990). Knowledge and strategies for processing lexical metaphors after right or left hemisphere brain damage. Journal of Speech and Hearing Research, 33, 307-316.
Winner, E. (1988). The point of words: Children's understanding of metaphor and irony. Cambridge: Harvard University Press.

Winner, E., Brownell, H., Happe, F., Blum, A., \& Pincus, D. (1998). Distinguishing lies from jokes: Theory of mind deficits and discourse interpretation in right hemisphere brain-damaged patients. Brain and Language, $62,89-106$

Winner, E., \& Gardner, H. (1977). The comprehension of metaphors in braindamaged patients. Brain, 100, 719-727.

Xiong, J., Rao, S., Gao, J.-H., Wodorff, M., \& Fox, P. T. (1998). Evaluation of hemispheric dominance for language using functional MRI: A comparison with positron emission tomography. Human Brain Mapping, 6, 4258 . 